\title{
Four-Stroke and Two-Stroke Marine Engines Comparison and Application
}

\author{
Eng. Waleed Alturki \\ Kuwait
}

\section{ABSTRACT}

Marine engines have evolved a lot through time. From the earliest instances of rowing equipment to the advanced machinery, propulsion engines have become a critical part in the efficiency of marine vessels. These engines can be classified and selected using various characteristics and types, such as its operating cycle. Engines can come in either the four-stroke or the two-stroke version. Four-stroke engines are primarily used in cars, buses, and trucks due to their lower noise production and higher stability in motion. Two-stroke engines are best used in scooters, motorcycles, ships, where space can present a constraint and noise is not an issue. Marine vessels favor the use of two-stroke engines as opposed to four-stroke ones due to fuel usage, engine efficiency, and power-to-weight ratio.

\section{INTRODUCTION TO MARINE ENGINES 1.1 Rudimentary Propulsion Sources}

The earliest instances of marine propulsion relied on natural phenomena instead of machines and engines. The wind was a primary source of propulsion for marine vessels. Sailing boats are known to have existed as early as 5500 $\mathrm{BC}$, as discovered on Mesopotamian artifacts (Bergman). Individuals during the primitive times also took note of a swimmer's way of propelling himself across water, and applied this method resulting to the use of paddles (Taggart 1). This expanded into galleys, a ship that made use of a large number of oarsmen. Galleys were used in warfare, due to its size and speed, until around 800 BC (Schulz).

\subsection{Steam Engine}

The first steam engines used wood, coal, and fuel oil to power the vessels. The fire heats up a boiler full of water in order to produce steam. The steam is redirected by a series of attachments which leads to the machine system of the vessel. In 1807, the first commercially successful marine steam engine was launched by an American engineer and inventor, Robert Fulton. The steampowered vessel traversed the Hudson River from New York City to Albany at the speed of 5 miles per hour (Ricci). At this point, the trip's usual sailing time was 96 hours, and Fulton's steam engine reduced the 150-mile journey to 32 hours.

\subsection{Steam Turbine}

As a development to the pistons used in steam engines, the steam turbine was invented. The steam turbine combined the optimal features of wind turbines and water turbines to produce a highly efficient machine. The spinning blades of a steam turbine reproduced to that of a wind turbine. From the water turbine, the steam turbine based its tight fit within an outer container, forcing the steam to have a higher velocity within the constrained environment (Woodford).

Steam turbines were found to be much more convenient than steam engines to use in marine vessels, as the turbine had a more compact size.

\subsection{Gas Turbine}

Similar to its other counterparts, the gas turbine makes use of rotating blades to power its machinations. A pressurized gas is produced by the engine, usually through burning natural gases, propane, kerosene, or jet fuel. Due to the heat from the burned fuel, air expands, increases in temperature, and rushes at high speed, spinning the blades of the turbine (Brain). While the gas turbine was found to be highly useful, it had several drawbacks when applied to marine vessels. The presence of salt within the air, as is common in the sea, allows for deposits to accumulate on the turbine's components. Engine parts had to be protected from corrosion and performance degradation (Leduc).

\subsection{Stirling Engine}

The Stirling engine, named after its inventor Robert Stirling, was invented in 1816. It produces mechanical energy by transferring heat to the engine's operational gas. The gas, within a completely isolated system, then initiates the movement of the engine's pistons (Saab Solutions). Its key advantage lies within the fixed amount of gas within the closed system, allowing manipulation of pressure and temperature as needed. However, since the heat is sourced externally, a higher latency can be observed in engine warm-up and power changes. Stirling engines, while potentially more efficient than gasoline or diesel-powered engines (Nice), are only 
used in specialized applications where silent operations are critical. These applications include primary or auxiliary power generators for submarines and yachts.

\section{FOUR-STROKE ENGINE \\ 2.1. History of the Four-Stroke Engine}

The Four-Stroke Engine is mostly credited to the German engineer Nicolaus Otto. His start on the engine was prompted by the work of the Belgian engineer Jean J. Lenoir on two-stroke coal gas engines. Otto sought to improve upon Lenoir's design, pointing out several reasons for its inefficiency. One such reason was that the gas used in the two-stroke engine is not compressed, therefore decreasing the productivity of the public supply for the coal gas, and were therefore only available to stationary machines.

The Otto cycle was further refined throughout the years, finally patented in 1877 . This innovation paved the way for engine development, ushering an age of automotive (Scoltock).

The first documented marine vessel that used four-stroke diesel engines is the Selandia. The ship sailed the ocean with 8-cylinder four-stroke engines, housed within enormous containers more than twice the height of an average sailor (Marine Diesels).

\subsection{Engine Process}

The four-stroke engine makes use of four distinct piston strokes for its operating cycle (see fig. 1). This internal combustion engine's cycle requires two passes within the cylinder, completing two $360^{\circ}$ revolutions of the crankshaft and the piston. Its cycle follows the sequence induction stroke, compression stroke, power stroke, and exhaust stroke (University of Windsor).

The first revolution pulls in the air-fuel mixture and compresses it, while the second process. Furthermore, Lenoir's engine relied on

revolution burns the fuel-air mixture and clears out the exhaust gases (Woodbank Communications). The engine's crankcase also contains lubricating oil, kept away from the combustion chamber, to be pumped separately to the bearing surfaces. The input and output valves control the flow of the fuel within the engine. The valves' openings should follow a precise timing in order to achieve maximum efficiency during the combustion process. This is especially important because power is only produced during the Power Stroke, and the other strokes rely on the inertia of a flywheel on the crankshaft for their movement.
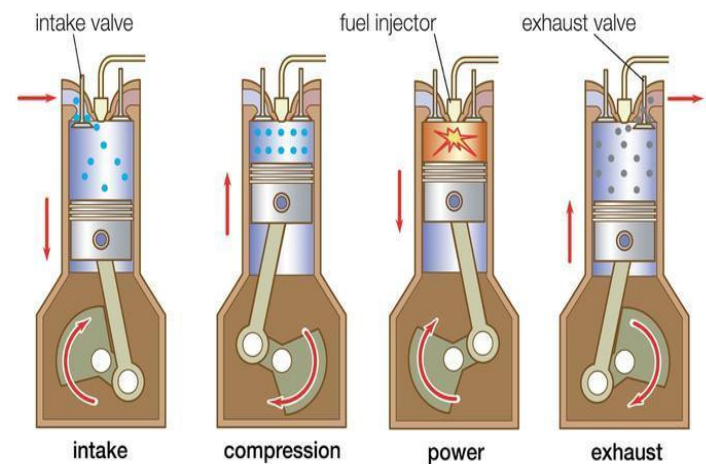

Fig. 1. The Distinct Piston Strokes in a Four-Stroke Engine. Encyclopaedia Britannica, Universal Images Group, Getty Images.

\subsection{Induction Stroke}

The first piston stroke is the Induction Stroke, also referred to as the intake or suction stroke. In this part of the cycle, the pistons starts at the top center of the cylinder (see fig. 2. 1), and ends up at the bottom center (see fig. 2. 2). The intake valve should be open while this stroke occurs, as the piston pulls in a mixture of air and fuel into the cylinder through vacuum pressure.

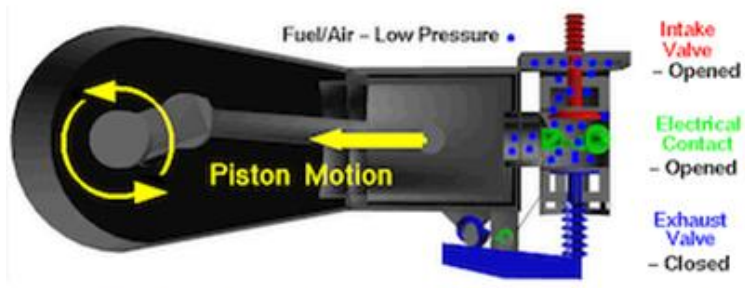

Fig. 2. 1. Initial Position of Induction Stroke.

Glenn Research Center; National Aeronautics and Space Administration, https://www.grc.nasa.gov/www/K12/airplane/engopt.html.

\subsection{Compression Stroke}

The Compression Stroke starts at the bottom center of the cylinder, and ends up at the top center. This step simply compresses the air-fuel mixture (see fig 2. 3) pulled in by the Induction Stroke, preparing

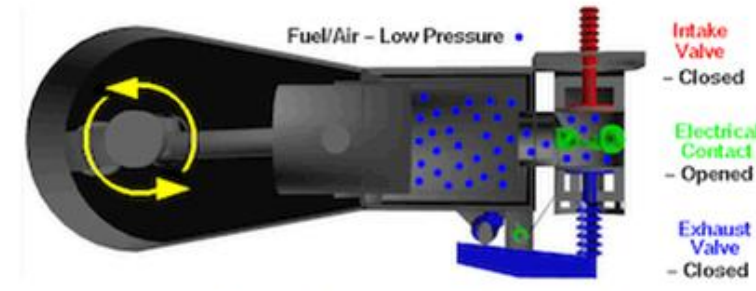

Fig. 2. 2. Final Position of Induction Stroke. 


\subsection{Power Stroke}

The Power Stroke, commonly referred to as ignition or combustion stroke, starts the second cylinder pass of the four-stroke cycle process. The crankshaft has already completed an entire revolution at this point. The air-fuel mixture inside the cylinder is ignited using a spark plug or high-

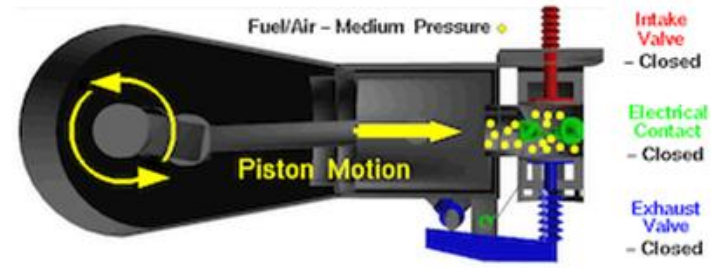

Fig. 2. 3. Compression Stroke.

Glenn Research Center; National Aeronautics and Space Administration, https://www.grc.nasa.gov/www/K12/airplane/engopt.html.

\subsection{Exhaust Stroke}

The Exhaust Stroke is the final stroke in the process. It is also called the outlet stroke. The piston begins at the bottom center (see fig. 2. 5) of

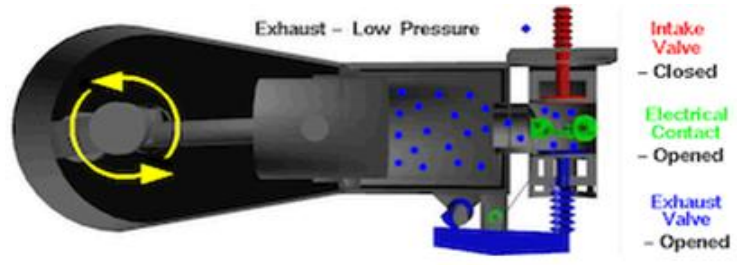

Fig. 2. 5. Initial Position of Exhaust Stroke. compression-generated heat, while the piston is currently positioned at the top center of the cylinder (see fig. 2. 4). This stroke produces mechanical energy that forcefully moves the piston to the bottom center of the cylinder, turning the crankshaft of the engine. the cylinder to the top center (see fig. 2. 6). The exhaust valve is opened, and the mixture of air-fuel is released through this exit.

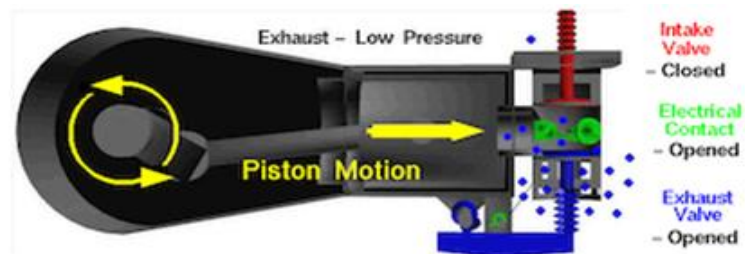

Fig. 2. 6. Final Position of Exhaust Stroke.

Glenn Research Center; National Aeronautics and Space Administration, https://www.grc.nasa.gov/www/K12/airplane/engopt.html.

\subsection{Four-Stroke Cycle Thermodynamics}

The operation of the engine relies heavily on the gas pressure and specific volume within the cylinder. Its indicator diagram (see fig 2. 7) shows the evolution of pressure and volume of the fourstroke engine as it completes its cycle.

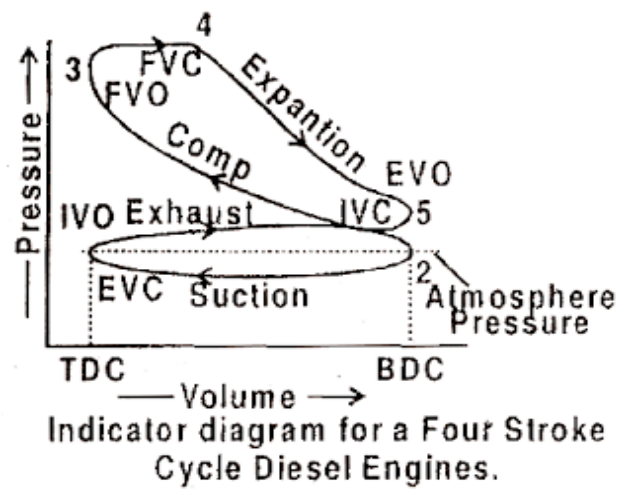

Fig 2. 7. Indicator Diagram for a Four-Stroke Engine. 4MechTech, http://4mechtech.blogspot.com/2013/12/indicator- diagram-or-pv-diagram-actual_9.html.

The Induction Stroke is indicated by the line going from point 1 to point 2 , under the atmospheric pressure value line (dotted). Due to this pressure difference, the air flows to the cylinder, increasing its volume. However, since the inlet valve moderates the amount that flows at any given time, the pressure within the cylinder remains beneath the atmospheric pressure. The Compression Stroke, indicated by the line going from point 2 to point 3 , significantly decreases the volume while greatly increasing the pressure as well. This is due to the gas being compressed inside the cylinder. For the Power Stroke follows the graph from point 3 to point 4 during ignition, increasing the pressure while the volume of the gas remains somewhat constant. The gas then expands, following the line from point 4 to point 5 . As can be seen, the pressure is lifted from the gas and its volume steadily rises. The Exhaust Stroke is graphed by the return from point 5 to the cycle's starting point 1 , showing the release of the gases 
out of the engine, decreasing the volume. The pressure is modulated by the exit valves that prevent gases from rushing out, so that the cylinder's pressure does not drop rapidly.

\subsection{Engine Power Limitation}

For the four-stroke engine, its generated power is limited by the amount of air used by the machine. In addition, the power is also dictated by the cylindrical volume of the piston. The speed by which the piston moves is capped by the strength of the material used and the available lubrication for the moving parts. High-speed movement will cause the lubrication to degrade. Acceleration forces are also applied on valves and pistons, causing potential machine breakage and power loss when the engine tries to go beyond its recommended speed. The oscillation of the engine should also be monitored, since the latency in the reaction time of the engine's valve springs could cause piston-tovalve contact, which is a source of damage for the machine.

\section{TWO-STROKE ENGINE}

\section{1.History of the Two-Stroke Engine}

The development of the two-stroke engine was spread throughout several decades. It began with the Scottish engineer Dugald Clerk, who presented the first commercial two-stroke engine. His work improved upon the design of the FourStroke engine, which only had one power stroke, causing a loss in the efficiency of the overall process.

Clerk's design was a double cylinder, with a cylinder called the displacer and another one called the power. The displacer cylinder pulls in the gas and air, compresses them slightly then transfers the compressed mixture into the power cylinder (Museum of Applied Arts \& Sciences). This dual cylinder configuration was released by Clerk in 1880, with the product manufactured by Messrs
Thomson, Sterne \& Co of Glasgow, and was patented in 1881.

Englishman Joseph Day improved this further by using the space beneath the engine's piston as a charging pump, rendering the engine as "valveless". The air charged under the piston helps clear out the remaining exhaust gases within the cylinder and regulate the temperature of the machine as well (Klooster 239). This design is sometimes called the crankcase-scavenged engine.

However, the first practical two-stroke engine was presented by the Yorkshireman inventor and engineer Alfred Angas Scott. He used a twin-cylinder water-cooled design in motorcycles that gave Scott motorcycle racers a huge edge from 1908 to 1912 (Moss).

\section{2.Engine Process}

The process of two-stroke engines is the same as that of a four-stroke, but is completed within only one revolution of the crankshaft. The engine is designed in such a way that the Induction, Compression, Power, and Exhaust steps could occur simultaneously between the two-stroke cycles (Baviskar). This innovation allows for greater efficiency within the process.

\section{3.Induction Step}

The Induction Step, also called the intake or suction step, pulls in the fuel and air mixture into the crankcase, regulated by a poppet intake valve (see fig. 3. 1), cylinder wall port, reed valve, or rotary disc valve.

\section{4.Crankcase Compression Step}

The Crankcase compression occurs during the downward stroke of the piston. The valve is forced closed due to the high pressure within the crankcase (see fig. 3. 2). As a result, the mixture is compressed within the crankcase during this step.

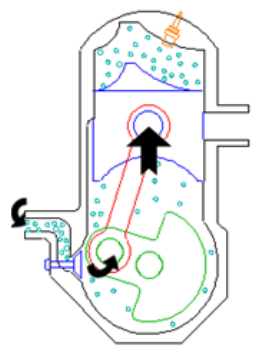

Fig. 3. 1. Induction Step.

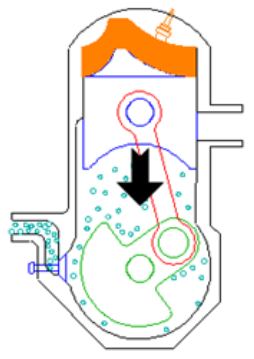

Fig. 3. 2. Crankcase Compression Step.

Matt Keveney; Animated Engines, http://www.animatedengines.com/twostroke.html.

\section{5.Transfer Step}

At the Transfer Step, the compressed air-fuel mixture moves from the crankcase towards the main cylinder (see fig 3. 3). This movement also helps in the expulsion of the previous contents of the main cylinder, aiding in the previous cycle's Exhaust Step. A downside to this step is that fresh fuel can also be expelled along with the exhaust 
gas.

\section{6. Compression Step}

The Compression Step compresses the air-fuel mixture within the main cylinder of the engine (see

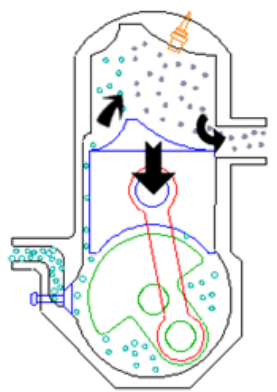

Fig. 3. 3. Transfer Step. fig 3. 4) as the piston rises. This movement is caused by the flywheel momentum. During his point, the Induction Step for the next cycle is also happening underneath the piston.

Matt Keveney; Animated Engines, http://www.animatedengines.com/twostroke.html.

\section{7.Power Step}

The spark plug ignites the fuel mixture during the Power Step. As the burning mixture expands, the piston is driven downward, completing the two-stroke cycle (see fig 3. 5). The Crankcase Compression Step for the next cycle occurs at the crankcase during the Power Step of

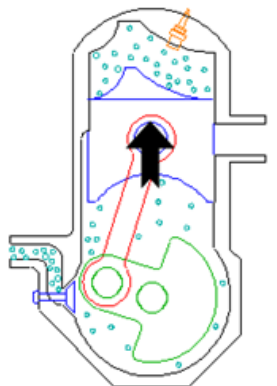

Fig. 3. 4. Compression Step.

the current cycle.

\section{8. Exhaust Step}

The exhaust gases produced are released during the Exhaust Step (see fig 3. 6). Simultaneously, the Transfer Step of the next cycle happens at this point.

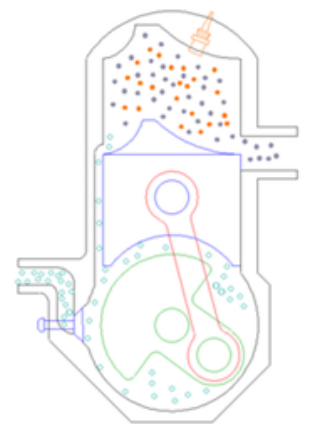

Fig. 3. 5. Power Step.

Fig. 3. 6. Exhaust Step.

Matt Keveney; Animated Engines, http://www.animatedengines.com/twostroke.html.

\section{9.Two-Stroke Cycle Thermodynamics}

The evolution of pressure and volume of the gas used in a two-stroke engine is similar to that of a four-stroke. As graphed by the indicator diagram (see fig. 3. 7), the two-stroke engine's cycle is comparable to the pressure-volume graph of an Otto cycle.

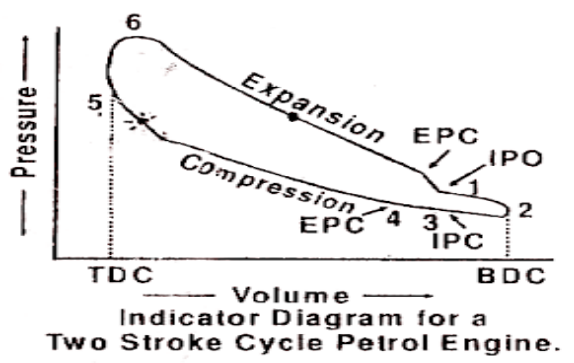

Fig 2. 7. Indicator Diagram for a Two-Stroke Engine. 4MechTech,

http://4mechtech.blogspot.com/2013/12/indicatordiagram-or-p-v-diagram-actual.html.

The Induction Step, shown by the curve from points 1,2 , and 3 , occurs during the time between the opening and closing of the inlet port. During this time, the exit port is also open due to the Exhaust Step of a previous cycle. As such, volume increases slightly, but also decreases right after. The exit port is then closed by point 4 . For the Compression Step, the graph moves from point 4 to point 5 . This shows a huge increase in the gas pressure inside the cylinder, while having a large decrease in volume as well. The Power Step occurs and the ignition increases the gas pressure and 
temperature within the cylinder. The volume only increases moderately during this stage, as can be seen from point 5 to point 6 . The Exhaust Step, drawn by the line from point 6 back to point 1 , shows the release of the gas following the opening of the exit port. Volume significantly increases while the pressure of the gas decreases. The cycle can now begin again from its initial stage.

\section{10. Engine Design}

There are several variations to the design of the two-stroke engine. Common examples include the piston-controlled inlet port, rotary inlet valve, and the crossflow-scavenged valve. A piston-controlled inlet port manages the flow of the air-fuel mixture by moving up and down the cylinder, effectively covering and uncovering the ports of the engine. Yamaha further improved this mechanism in the 1970s, establishing the basic functionalities.

The rotary inlet valve closes and opens the ports using a rotating part such as a disk valve. Some variations of this design use rotating cylinders with coinciding openings in order to mediate the flow of the fuel. The crossflowscavenged variation is now only used amongst smaller machinery, especially those who do not necessarily need high speed. It is designed in such a way that the ports are on opposite sides of the cylinder, and a deflector is utilized in order to control the direction of the air-fuel mixture.

\section{RECOMMENDATION 4. 1. Recommendation for Ship Engines}

In the construction of a ship, the selection of its main propulsion machinery is one of the critical decisions. The four-stroke and two-stroke engines are both widely used in the market; however, for large marine vessels, especially those heading out into the ocean, the two-stroke engine is more commonly installed. The four-stroke engine, while having a compact plant size and a higher revolution rate, is outshined by the two-stroke engine in several factors (Wankhede).

\section{2.Fuel Usage}

While the two-stroke engine consumes fuel per two strokes, as opposed to the per four strokes of the four-stroke engine, it also has the advantage of being able to burn low-grade fuel oil. A high cost reduction can be applied in such cases, and would therefore be more profitable, which is a huge advantage for merchant ships.

\section{3.Engine Efficiency}

Comparing the two-stroke and four-stroke engines under a standard operating setting, the design of the two-stroke engine is more efficient as it reduces thermal and mechanical losses. In addition, energy is conserved more since the twostroke engine has less heat transfer from the engine to the cooling system than that of the four-stroke.

\section{4.Power-to-Weight Ratio}

Since two-stroke engines are lighter and result in a higher power-to-weight ratio (AMSOil), ships that use this engine instead of the four-stroke can load more cargo with the same amount of power. Ships are often used for transferring heavy material, so this would be a huge advantage to the two-stroke engine vessels.

It should be noted, however, that the fourstroke engine has a greater maneuverability than that of a two-stroke. There is also a great discrepancy between the installation cost of a twostroke engine plant and the maintenance cost of a four-stroke engine. However, with all factors considered, the categorical recommendation for merchant and cargo ships is the two-stroke engine.

\section{5. Recommendation for Outboard Boat Engines}

Two-stroke engines used to use carburetors as a way of controlling the air-fuel mixture. However, the efficiency of carbureted outboards left a lot to be desired: the fuel intake was extremely high, and often became uncooperative.

As a result, an innovation that uses the power of technology came to be. Two-stroke engines now use a computerized system called Direct Fuel Injection, commonly known as DFI, in order to optimize the air-fuel mixture in relation to the engine's operating environment. Using this technology, the engine's performance, fuel efficiency, and emission rates have become significantly better (Boyt).

In outdated two-stroke engines, used in outboard marine and personal watercraft engines such as jet boats, the emission of pollutants like hydrocarbons and nitrogen oxides have reached alarming rates. The exhaust emissions from several hours of watercraft operation is equivalent to that of a 1998 automotive with at least a mileage of 100,000 miles (California Air Resource Board). Conventional two-stroke engines have been reported to discharge as much as 25 to 30 percent of their fuel, unburned and unconverted, into the water. The following table (see table 1) lists the exhaust emissions of watercrafts in California. 


\begin{tabular}{|l|l|l|l|l|l|l|}
\hline Equipment Type & Population & HC & NOx & HC+NOx & CO & PM \\
\hline Personal Watercraft & 161,898 & 246 & 2 & 248 & 414 & 13 \\
\hline Outboards & 346,372 & 63 & 1 & 64 & 120 & 4 \\
\hline Total & $\mathbf{5 0 8 , 2 7 0}$ & $\mathbf{3 0 9}$ & $\mathbf{3}$ & $\mathbf{3 1 2}$ & $\mathbf{5 3 4}$ & $\mathbf{1 7}$ \\
\hline
\end{tabular}

Table 1. 1997 Statewide Recreational Marine Engine Emissions. California Air Resource Board, https://www.arb.ca.gov/msprog/offroad/recmarine/msc98-08/workdoc2.pdf.

The two-stroke outboards are usually lighter than their four-stroke counterparts since they operate without valves. Less moving parts in the two-stroke engines equate to less rotating mass, and thus a higher potential acceleration given the same horsepower used by a four-stroke engine. The engine's inner parts are also lubricated by the oil mixed in the fuel.

Some may say that two-stroke engines are becoming less used in outboards. However, it is the carbureted two-stroke engines that are declining in usage while the DFI ones are steadily making their way to the top. With their many benefits, the DFI two-stroke engines are here to stay. Therefore, when choosing an engine for outboards, DFI twostroke engines are the best recommendation.

\section{CONCLUSION}

The four-stroke engine, one of the pioneer designs to improve fuel combustion efficiency, follows the sequence of induction, combustion, power, and exhaust strokes in four revolutions of its crankshaft. It was considered a breakthrough in the field of engine development, and many other engineers sought to improve upon it. The fourstroke engine worked great for its original purpose in the automotive industry, and is still being widely used by cars and trucks today. This engine also became a popular choice in marine vessels at one point, but was eventually overtaken by the twostroke engine.

The two-stroke engine aimed to address the efficiency loss in the four-stroke combustion process. The sequence of the two-stroke engine remains the same; however, its advantage lies in the dual compartments of the engine. The steps within the cycle can run simultaneously with other steps from other cycles, allowing the process to take place within only two revolutions of the engine's crankshaft. The two-stroke engine is light and has a higher power-to-weight ratio; it became a profitable option especially for merchant and cargo ships. It is also commonly used by scooters and motorcycles.

Marine vessels, such as ships and carriers, have migrated more and more to the two-stroke engine. While four-stroke ships still exist, the twostroke engines are becoming more optimal and cost-efficient for the companies. Smaller vessels, like the outboards and personal boats, also use twostroke engines, especially with the onset of highly customizable fuel injections for these engines.

\section{WORKS CITED}

[1] AMSOil. "2-4 Stroke Engine Applications and Lubrication Needs." Synthetic Oil, Motor and Engine Oil, Lubricants, Air Filters, Oil Filters and Greases, n. d. Accessed 12 March 2017.

[2] Baviskar, Jay. "How does a 2 stroke engine work?" MechStuff, 11 October 2015. Accessed 12 March 2017.

[3] Bergman, Jamey. "10 top innovations in the history of sailing." Yachting \& Boating World, 9 March 2016. Accessed 12 March 2017.

[4] Brain, Marshall. "How Gas Turbine Engines Work.” HowStuffWorks.com, 1 April 2000. Accessed 12 March 2017.

[5] Boyt, Lee. "How to Decide Between a Twoor Four-Stroke Outboard Boat Engine." Game \& Fish, 25 July 2011. Accessed 12 March 2017.

[6] Klooster, John. Icons of Invention: The Makers of the Modern World from Gutenberg to Gates. ABC-CLIO, 2009. Web.

[7] Leduc, Martin. "The Gas Turbine." Dieselduck.net, March 2001. Accessed 12 March 2017.

[8] Marine Diesels. "The 4 Stroke Diesel Cycle.” MarineDiesels.co.uk, 2001. Accessed 12 March 2017.

[9] Moss, Roger. "A Short history of Scott Motorcycles." Moss Engineering, December 2011. Accessed 12 March 2017.

[10] Museum of Applied Arts \& Sciences. "Stockport two-stroke horizontal gas engine." 2015. Accessed 12 March 2017.

[11] Nice, Karim. "How Stirling Engines Work." HowStuffWorks.com, 4 May 2000. Accessed 12 March 2017.

[12] Ricci, Tom. "Robert Fulton." The American Society of Mechanical Engineers, May 2012. Accessed 12 March 2017.

[13] Saab Solutions. "The Stirling Engine." n. d. Accessed 12 March 2017.

[14] Schulz, Stephan. "Ancient Galleys." 7 January 2004. Accessed 12 March 2017.

[15] Scoltock, James. "Nicolaus Otto developed the four-stroke combustion engine." Automotive Engineer, 1 June 2010. 
Accessed 12 March 2017.

[16] Taggart, Robert. "Early Developments In Marine Propulsion." Journal of the American Society for Naval Engineers, vol. 70, no. 2, 1958, pp. 91-208.

[17] University of Windsor. "Four Stroke Cycle Engines." n. d. Accessed 12 March 2017.

[18] Wankhede, Anish. "Why 2-stroke Engines Are Used More Commonly Than 4-stroke on
Ships." Marine Insight, 21 July 2016. Accessed 12 March 2017.

[19] Woodbank Communications. "Piston (Reciprocating) Engine Power Plants." Battery and Energy Technologies, n. d. Accessed 12 March 2017.

[20] Woodford, Chris. "Steam Turbines." 25 September 2016. Accessed 12 March 2017. 